DR. GEORGE OLAH (Orcid ID : 0000-0002-7935-8843)

DR. JAVIER NORI (Orcid ID : 0000-0002-7127-7934)

Article type : Primary Research Articles

\title{
Global trends of habitat destruction and consequences for parrot conservation
}

Running title: Global trends in parrot conservation

David L. Vergara-Tabares ${ }^{1}$, Javier M. Cordier ${ }^{1}$, Marcos A. Landi ${ }^{1}$, George Olah ${ }^{2,3}$ \& Javier Nori ${ }^{1}$,

${ }^{1}$ Instituto de Diversidad y Ecología Animal (UNC-CONICET) \& Centro de Zoología Aplicada (UNC), Rondeau 798, X5000AVP, Córdoba, Argentina

${ }^{2}$ Wildlife Messengers, Richmond, VA 23230, USA

3 Fenner School of Environment and Society, The Australian National University, Canberra, Australia.

${ }^{4}$ Corresponding author: javiernori@gmail.com

\begin{abstract}
Human advance on natural habitats is a major cause of biodiversity loss. This transformation process represents a profound change in wooded environments, disrupting original communities of flora and fauna. Many species are highly dependent on forests, especially parrots (Psittaciformes) with almost a third of their species threatened by extinction. Most parrot species occur in tropical and subtropical forests, and given the forest dependence of most species, this is the main reason why habitat loss has

This article has been accepted for publication and undergone full peer review but has not been through the copyediting, typesetting, pagination and proofreading process, which may lead to differences between this version and the Version of Record. Please cite this article as doi: 10.1111/GCB.15135
\end{abstract}

This article is protected by copyright. All rights reserved 
been highlighted as the main threat for the group. Such habitat loss acts in synergy with other important threats (e.g. logging and poaching), which become especially problematic in certain developing countries along tropical latitudes. In this study, we used available information on parrot distributions, species traits, IUCN assessment, habitat loss and timber extraction for different periods, and distribution of protected areas, in order to determine conservation hotspots for the group, and analyze potential changes in the conservation status of these species. We detected four conservation hotspots for parrots: two in the Neotropics and two in Oceania, all of them facing different degrees of threat in regard of current habitat loss and agricultural trends. Our results suggest that the future of the group is subject to policymaking in specific regions, especially in the northeastern Andes and the Atlantic Forest. In addition, we predicted that agricultural expansion will have a further negative effect on the conservation status of parrots, pushing many parrot species to the edge of extinction in the near future. Our results have conservation implications by recommending protected areas in specific parrot conservation hotspots. Our recommendations to mitigate conservation risks to this group of umbrella species would also benefit many other coexisting species as well.

Key words: Anthropogenic threat; Psittaciformes; IUCN; Temporal analysis; deforestation; timber extraction; protected areas

\section{Introduction}

Human advance on natural habitats is a major cause of biodiversity loss (Ceballos et al., 2015). During the last three centuries, approximately 39\% of Earth's total ice-free surface was converted into agricultural land and settlements, and an additional 37\% of global land has become surrounded by anthropogenic biomes (Ellis, Goldewijk, Siebert, Lightman, \& Ramankutty, 2010). These processes of transformation represent a profound change in wooded environments, where native communities of flora and fauna are often replaced by monocultures and invasive alien species (Ficetola, Mazel, \& Thuiller, 2017). Many species of birds are highly dependent on forests. The order Psittaciformes (hereafter parrots) comprise one of the most threatened groups of birds (IUCN, 2018; Olah et al., 2016) and include a great proportion of forest dependent species. The order encompasses 398 species

This article is protected by copyright. All rights reserved 
divided into 6 families (Provost, Joseph, \& Smith, 2017; but see del Hoyo, Collar, Christie, Elliott, \& Fishpool, 2014 for considering 3 families), distributed across six continents, and representing one of the most species-rich groups of birds (Collar, 2018). Almost a third of the extant parrots (112 species) are threatened by extinction: 18 Critically Endangered (CR), 39 Endangered (EN), and 55 vulnerable (VU; IUCN, 2018). Parrots are not only affected by habitat loss but also by other human-induced threats. For example, many species are considered as valuable pets, mainly due to their colorful feathers, their capacity to mimic the human voice, and their tolerance to captivity (Forshaw, 2010). Human pressure on wild parrot populations has contributed to the decline of many species since the beginning of the 19 $9^{\text {th }}$ century (Forshaw, 2010; Forshaw \& Wright, 2017). Currently, the populations of $56 \%$ of parrot species are decreasing in numbers, and the advancing habitat destruction of tropical and subtropical forests represents the main threat to this group globally (Olah et al., 2016).

Although parrots are threatened by several human-induced factors, their long history of coexistence with human society is also a consequence of their charismatic image and intelligence, and many of them can be used as flagship species to conserve highly threatened regions (Fleishman, Murphy, \& Brussard, 2000; Snyder, McGowan, Gilardi, \& Grajal, 2000). Indeed, those characteristics of parrots and their high level of threat has recently highlighted the importance of parrot conservation, and by now, it became evident that this group is the most threatened bird order today (see special issue on parrots in Emu - Austral Ornithology 2018; Heinsohn, Buchanan, \& Joseph, 2018). In 2010, the International Ornithologists' Union established the Working Group on Psittaciformes (www.internationalornithology.org/psittaciformes). As a consolidated international effort, this current study follows the line of regional reviews on parrot extinction risk (Martin et al., 2014; Olah et al., 2016; Berkunsky et al., 2017, Olah et al., 2018), concerning the global threats of habitat destruction to parrots and evaluating their future in protected areas.

While agriculture, poaching, trapping, and logging have been highlighted as the most important drivers of parrot extinction risk (Wiley et al., 2004; Olah et al., 2016), their relative importance strongly differs among regions (Olah et al., 2016). Agricultural practices are the main threat to the group, and this threat is especially relevant in the Neotropics, one of the most species rich areas (Olah et al., 2016; Berkunsky et al., 2017). In other regions like Africa, parrots, such as the Psittacus species, are heavily threatened by poaching and logging (Martin et al., 2014; Martin, 2018). 
In addition, the introduction of alien species has been pointed out as the main threat for the taxa in the Pacific Islands, a center of endemism for the group with almost the half of them threatened (IUCN, 2018; Olah et al., 2018). These varied external factors often interact with species traits of parrots, such as large body size, narrow range of distribution, or forest dependence (Bennett \& Owens, 1997). In fact, over $70 \%$ of parrot species are forest dependent due to their feeding and breeding habits (i.e. parrots are secondary tree cavity nesters; Snyder et al., 2000; White, Collazo, \& Vilella, 2005). Therefore, they are strongly affected by different kinds of human activities in forested regions, and most of them are extremely sensitive to the reduction of nesting sites caused by forest destruction (Newton, 1994).

Forests are highly threatened by agriculture and urbanization, processes in which original habitats become heavily fragmented or disappear entirely (Brooks et al., 2002; Hansen et al., 2013; Laurance et al., 2012), seriously threatening biodiversity (Fischer \& Lindenmayer, 2007; Foley, 2005; Jetz, Wilcove, \& Dobson, 2007; Sala et al., 2000). Although this process operates at the global scale, its intensity and dynamic are temporally and spatially heterogeneous. The most threatened areas are the tropical and subtropical forests, which are also the major reservoirs of global biodiversity and hotspots of parrot diversity (Gibson et al., 2011; Laurance et al., 2012; Olah et al., 2016; Scholes et al., 2018). The future perspectives of forest loss are highly dependent on both biophysical and socioeconomic factors (Verburg, Ellis, \& Letourneau, 2011), and as almost all the countries harboring tropical and subtropical forests are emergent or developing countries, their economies are supported by primary production (Sloan \& Sayer, 2015).

Therefore, the main drivers of forest loss are commercial agriculture and subsistence agriculture (both including forest clearing for cropland), pasture and tree plantations, and permanent subsistence and shifting cultivation (Hosonuma et al., 2012). Besides, forest clearing accelerates the human intrusion to adjacent forests and allows the exploitation of additional resources such as timber, bush meat, and animals (Cullen, Bodmer, \& Pádua, 2000; Ripple et al., 2016; Torres et al., 2018).

Logging and poaching are commonly associated with the edges of deforested areas and usually coexist (Brodie et al., 2014). While poaching for the illegal pet trade directly impacts parrot populations by the extraction of individuals (Pires, 2012), logging has an indirect but long-lasting negative effect on these populations by reducing their nesting sites (Heinsohn et al., 2003; Olah et al.,

This article is protected by copyright. All rights reserved 
2014). Forest loss (and its inherent human activities, such as logging and poaching) is expected to continue and increase in the future in the Americas, Africa, and Asia (following the model proposed by Hosonuma et al., 2012; Chini, Hurtt, \& Frolking, 2014). In this regard, it is unknown how these processes of forest loss and degradation will impact habitat availability for parrots and their distribution in the future, but most likely negatively.

In the context of forest loss and other human disturbance (e.g. logging and poaching), protected areas (PAs hereafter) play a crucial role in maintaining biodiversity and are thus the cornerstone of in situ conservation (Pollock, Thuiller, \& Jetz, 2017). Unfortunately, in the past PAs have been allocated without proper assessments on species distribution or their ecological needs (Rodrigues et al., 2004; Nori et al., 2015; Venter et al., 2014; Pressey, Whish, Barrett, \& Watts, 2002; Vergara-Tabares, Lammertink, Verga, Schaaf, \& Nori, 2018; Vieira et al., 2019). In general, PAs are designated due to their scenic beauty, or in areas where the value of land is cheap because of the low potential for extractive and/or agricultural production (Venter et al., 2014; Pressey, Visconti, \& Ferraro, 2015). The dominantly residual nature of PAs, in concordance with their management problems (Watson, Dudley, Segan, \& Hockings, 2014) and their relatively high degree of human disturbance (Jones et al., 2018), are the main reasons that PA networks can be inadequate at representing and protecting biodiversity (see Rodrigues et al., 2004; Venter et al., 2014; Nori \& Loyola, 2015; Nori et al., 2015). In that regard, birds are often poorly represented in PAs, and this representation of birds in PAs varies at different spatial scales and in different locations (VergaraTabares et al., 2018; Prieto-Torres, Nori, \& Rojas-Soto, 2018). Given these patterns of forest loss and other human disturbances, evaluating the representativeness of parrots within current PA networks may better inform policies for their conservation.

In this study, we use parrots as our model group, given their high forest dependency, the multiple anthropogenic threats they face, and their potential as a surrogate group for conservation planning to explore how the temporal variation in forest loss (considering past and future land-use scenarios) affects the extinction risk of this group in a global context. Specifically, we aimed to (i) identify hotspots for parrot conservation, based on forest dependent species richness, their conservation status, and land-use trends; (ii) analyze potential changes in extinction risk of parrots considering land-use change, human pressure (logging and poaching), forest dependency, and 
population trends under the thresholds imposed by IUCN (focusing on habitat availability); and (iii) study the efficiency of the current global network of PAs to represent parrot diversity worldwide.

\section{Methods}

\section{Spatial database construction}

After requesting online access, we received the link to download digital range maps (extent of occurrence maps) for 398 parrot species. This distribution data (digitalized maps in geodatabase format for use in GIS mapping software) is compiled by BirdLife International, and Handbook of the Birds of the World (2018; see http://datazone.birdlife.org/species/requestdis). Using the spatial join tool of ArcGIS 10.3, we associated each range with the IUCN RedList conservation status of the species (from LC to CR), their recent population trend (IUCN, 2018), and three different habitat needs of the species (hereafter forest dependency). This corresponds with an international and widely accepted classification, where experts classified birds into 3 categories based on their dependence on forest environments: (1) highly forest dependent species that only occupy forest environments, (2) medium forest dependent species, and (3) low or non-forest dependent species (extracted from BirdLife International and Collar, 2018). We also included the altitudinal range occupied for each species to the attribute table. We calculated the distribution area for each species in $\mathrm{km}^{2}$.

Global land cover maps with a resolution of $300 \mathrm{~m}$ for the year 2000 were downloaded from ESA Climate Change Initiative (2017). This source provides the highest resolution images of forest loss at global scale for this period. Then, the maps were reclassified in ArcGIS 10.3 in order to generate a new binary raster, discriminating those areas occupied by agricultural crops (i.e. pixels with at least $50 \%$ of their surface occupied by crops) and urban settlements from all the other categories. For the current global land cover (i.e. 2018), we downloaded and compiled images provided by the Tree Cover Loss platform (Hansen et al., 2013; https://earthenginepartners.appspot.com/science-2013-global-forest) with a resolution of $30 \mathrm{~m}$. With these images we assembled a binary raster using the same taxonomic criteria as for the land cover for the year 2000 (see above). Given that the Tree Cover Loss platform only provides images of forest loss from 2000 to 2018 (but does not register forest loss previous to 2000), these images were 
combined with global land cover from ESA (showing land cover from previous periods) in order to obtain an image with the current complete picture of global forest loss. We also used predicted layers of forest loss and urban areas by the year 2050 from the Harmonized Global Land Use (Chini et al., 2014) with a spatial resolution of 0.5 square degrees, which provided the first consistent set of landuse change and emission scenarios for studies of human impacts on the past and future global carbonclimate system. Among the available future scenarios (combinations of different socioeconomic pathways and radiative forcing scenarios), we selected "the middle of the road (SSP2)" as a socioeconomic pathway which considers that the world follows a path in which social, economic, and technological trends do not shift markedly from historical patterns (See Chini et al., 2014 for technical details). We used the RCP4.5 as radiative forcing scenario (Hayhoe et al., 2017) that considers medium carbon emission and medium mitigation actions, both coherent with the SSP2 model.

To evaluate the influence of other human threats associated with forest loss, we used a global map of timber extraction (Hurtt et al., 2011) as a proxy for logging. We downloaded this map for 2018 and 2050 from the Harmonized Global Land Use (Chini et al., 2014). These global layers are built under our selected socioeconomic pathways (SSP2) and radiative forcing scenarios (RCP4.5). This source provides a temporal series of predicted timber extraction and allows to select the global prediction for any year between 2005 and 2100 . These layers provide an estimation of timber extraction per grid cell measured in Ton $/ \mathrm{km}^{2}(1$ metric ton $=1,000 \mathrm{~kg}$ ), so we only considered those grid cells that belong to the third and fourth quartiles (i.e. areas with the highest timber extraction). In addition, we reclassified the grid cells of the third quartile as high timber extraction and those of the fourth quartile as very high timber extraction categories (for details of model construction and timber extraction estimation see Chini et al., 2014). From the different available environments for which wood harvest biomass can be calculated using Harmonized Global Land Use, we only considered: primary forest, primary non-forest (shrubs), secondary mature forest, secondary young forest, secondary non-forest (degraded shrubs). In this way we avoided including wood biomass from tree plantations into the analyses, which could generate strong bias.

Finally, we obtained shapefiles of terrestrial PAs around the globe from the World Database on PAs website (IUCN \& UNEP, 2019). We only selected those terrestrial PAs with the "designated" status (i.e. we did not consider PAs with "inscribed", "non-reported", or "proposed" status), from I to 
IV management categories defined by the IUCN (i.e. categories which have specific conservation objectives), totaling 85,378 protected areas. The shape file of the selected PAs was rasterized at a spatial resolution of $1 \mathrm{~km}$ in ArcGis 10.3.

\section{Data analysis}

We used the 'raster' (Hijmans et al., 2015) and 'maptools' (Bivand et al., 2017) packages of R statistics (R Core Team, 2014) in order to minimize the inaccuracy of distributional polygons (see Ficetola et al., 2014). We overlapped each polygon with a raster of altitude at spatial resolution of 1 $\mathrm{km}$, so we were able to extract those pixels of each distribution inside the known altitudinal range occupied by species. This methodology allowed us to generate individual rasterized distribution for each species by refining the information of their polygon with ecological information of their altitudinal ranges.

\section{(i) Identifying hotspots for parrot conservation}

In order to take into account species richness and also their extinction risk and forest dependency in subsequent analyses, we performed a weighted map of parrot richness. First, we multiplied the individual raster of each species by a value corresponding to its conservation status. We used an ordinal scale for the conservation status $(\mathrm{LC}=1 ; \mathrm{NT}=2, \mathrm{VU}=3 ; \mathrm{EN}=4 ; \mathrm{CR}=5)$ given that the trends in the resulting index are driven by a relatively large number of species (hence producing a more robust and representative index). This is because a species moving from LC to NT contributes just as much to the changing score as a CR species going Extinct, and the numbers of species in each category (and the number moving in and out of each category) increases disproportionately from LC to CR (Butchart et al., 2004). After this, each resulted raster value was multiplied by the forest dependence of the species (low or no forest dependence $=0$; medium dependence $=1$; high dependence $=2$ ). Finally, these "weighted" rasters of individual species were overlapped in order to generate a raster of species richness weighted by the species' conservation status and forest dependency. We refer to the final values as "index value" representing not only the number of overlapping species but also their conservation status and forest dependency. Because species with low or no forest dependency were multiplied by zero, they were excluded from the final maps. We compared the final weighted map of richness with the non-weighted map of richness (where all the

This article is protected by copyright. All rights reserved 
species have an equal value of ' 1 ' independently of their conservation status and forest dependency) in order to evaluate if the inclusion of forest dependency and conservation status of species modify the non-weighted pattern of richness.

\section{(ii) Changes of extinction risk over time}

The weighted map of parrot species richness was overlapped with binary rasters of humandominated areas, and the portions of the maps of richness overlapping with these areas were extracted. Then, we superposed the map of richness in human-dominated areas with the original map of richness in order to generate a bivariate global map, showing the value of weighted richness in both human-dominated and wild habitats. We generated a bivariate map of weighted richness for three time periods: 2000, 2018, and 2050.

We calculated the distribution percentages for each species overlapping with both categories of land cover (human-dominated and wild) for each period, by using the 'maptools' (Bivand et al., 2017) and 'raster' (Hijmans et al., 2015) packages of R statistics (R Core Team, 2014). We overlapped the refined distributional map of each species and the binary land cover raster of each period and calculated those percentages. We also calculated the mean value of timber extraction per $\mathrm{km}^{2}$ across each parrot distribution for 2018 and 2050.

We identified those forest dependent species that currently had a decreasing tendency in population size and cross some of the thresholds imposed by the criterion B1 of IUCN. The criterion $\mathrm{B}$ is based on the geographic range of the species (B1 = extent of occurrence and/or B2 = area of occupancy) and imposed several thresholds to define their conservation category. To establish the conservation status of a species based on criterion B, it is also necessary to demonstrate at least two of the following conditions of their populations: (a) severely fragmented or known to exist at only a certain number of locations; (b) continuing population decline; and (c) extreme fluctuations in occupancy, subpopulations or mature individuals (IUCN, 2012). Although our approach to study the changes in extinction risk over time only considered the variation of the geographic range and population tendencies of parrots, it has been proven that habitat reduction induces fragmentation and increased extinction risk of species (Brook et al., 2008; Hanski, Zurita, Bellocq, \& Rybicki, 2013).

(iii) Efficiency of global PA network

This article is protected by copyright. All rights reserved 
Using the same methodology as above, we overlapped the individual raster of each species with the map of PAs and calculated the degree of representation for each species in the global network of PAs (mean \pm standard deviation).

\section{Results}

From the 398 parrot species, 76 had low or no forest dependency and hence were excluded from subsequent analysis. Out of the included species, 68.9\% (222 species) were categorized as nonthreatened (i.e. LC or NT; IUCN 2018). From the 100 remaining species, 48 were categorized as VU, 35 as EN, and 17 as CR. From the 76 non-forest-dependent species, only $14.7 \%$ were categorized as threatened, including seven VU, four EN, and one CR species.

Both weighted and non-weighted maps of richness (Fig. S1) indicated that the most important conservation hotspots for the group are located at the northeast of the Amazon forest, in the southern Amazon Basin, with a maximum index value of 44 in the weighted map of richness and 31 species in the non-weighted map of richness. There are other areas with high index values ranging from 22 to 33. These are located in South America (including the northern Amazon Basin, portions of the Tropical Andes, small areas confined within the Atlantic Forest, and the Cerrado; Fig. 1A), and in Australasia (including the temperate forest of southern Australia and the New Guinea highlands; Fig. 1B). The geographical pattern showed in the maps of weighted richness (Fig. 1) did not differ from the non-weighted maps using all parrot species (Fig. S1).

We found that human-modified environments are quickly encroaching over the most important areas for parrots, when overlaps between weighted richness and land-use changes in different timeperiods were analyzed. The most parrot species rich areas in South America (located in the eastern Amazon Basin) were practically intact in 2000 but human-modified environments increased in 2018, and our forecast for 2050 indicated a stabilization of intensive human activities in the region. Trends also indicated dramatic increases of human-dominated lands in other important Neotropical areas including the Brazilian Atlantic Forest, the Andes, intermontane valleys in Colombia, and Central America toward 2050 (Fig. 1A). On the other hand, trends in New Guinea and the central and western portions of the Amazon Basin and the tropical Andes indicated that parrot hotspots will not be heavily

This article is protected by copyright. All rights reserved 
threatened by intensive human activities in the near future (Fig. 1). The temperate forest of Australia and the large islands of Indonesia were already heavily degraded by human-modified landscapes in 2000, and the trends toward 2050 indicate that additional changes due to human activities will affect these regions in the near future (Fig. 1B). Finally, in Africa (with lowest parrot richness relative to the global parrot distribution) the land-use change will advance mainly in the west-central areas and in the mountains of the east-central part of the continent in the future (Fig. 1C).

We found that the most important hotspots for parrot diversity (northwestern Amazon and western New Guinea) will suffer very high rates of timber extraction (Figs. 2A and 2C) by 2050. According to our forecasts, this picture will be more extensive but less intense in the Amazon basin (Fig. 2A), and it will be greatly reduced in New Guinea by 2050 (Fig. 2C). In contrast, there is currently intensive timber extraction in central Africa, which would become exacerbated toward 2050 (Fig. 2B). In addition, some important regions without intensive timber extraction at the moment (e.g. central Bolivia and northeastern Argentina) are expected to suffer a drastic increase in habitat destruction in the near future (Fig. 2A). Finally, several scattered areas worldwide (including centralwestern Africa, eastern India, and many islands of Indonesia) are likely to continue extracting timber in a very high rate even in 2050 (Figs. $2 \mathrm{~B}$ and 2C).

On average, only $10.2 \%( \pm 13.4 \mathrm{SD})$ of the geographic range of all parrot species overlap with PAs. The results are similar when analyzed regionally, with the average overlap varying from $8 \%$ in America to $23 \%$ in Africa. Finally, when we considered the conservation status of the species in the analysis, the least represented species in PAs were those classified as CR (with $4.46 \%$ in America and 21.1\% in Australasia). The best represented groups of parrots in PAs were those categorized as EN with average overlap of $15 \%$ in Australasia, and those categorized as VU with $11.1 \%$ in America and $14.5 \%$ in Africa (Fig. 3).

Regarding forest dependent parrot species with decreasing population trends, our results show that some of these species inhabiting America, Southeast Asia, and Oceania could change their conservation status by 2050, given the current land-use trends. The species for which we expect a greater overlap with human-dominated environments will most probably cross at least one of the thresholds imposed by the B1 criterion of IUCN. We identified 26 species crossing these imposed thresholds: 10 in America and 16 in Australasia and Oceania (Fig. 4).

This article is protected by copyright. All rights reserved 


\section{Discussion}

In this work, we provide a global picture on the effect of human habitat transformation (for past, present, and future periods) for the conservation of forest dependent parrots, identifying particular areas where human encroachment would threaten important hotspots for their conservation. Some of these hotspots are heavily threatened today or show an uncertain future, pushing this most threatened bird order further down on the slope of extinction, hence, warning policymakers to generate more suitable conservation policies. Combining parrot richness with their conservation status and forest dependence, we detected four parrot conservation hotspots worldwide. These areas are in concordance with previous studies (e.g. Olah et al., 2016): two in the Neotropics (eastern Amazon Basin and the northeastern Andes) and two in Australasia/Oceania (New Guinea and southeastern Australia). With respect to the land-use trends analyzed in this study, the current situation for parrot conservation clearly differs among these hotspots, with more worrying predictions in southeastern Australia and the northeastern Andes. In addition, it is expected that these differences will increase in the future. The areas of New Guinea and the Amazon Basin have currently a low overlap with humanmodified landscapes, with little change expected by 2050. In contrast, the area located in southeastern Australia shows a great overlap with human-modified landscapes, with a substantial increase expected in the future. While the current overlap with human-modified environments is low in the northeastern Andes, one of the most important parrot conservation hotspots, a great increase is expected by 2050 . Most importantly, all parrot conservation hotspots are affected by intensive timber extraction, which also affect parrot populations by reducing availability of nesting sites and/or increasing the

accessibility to poaching activities (Brodie et al., 2014). Additionally, the size of the areas affected by these threats is expected to increase in the near future, while the intensity of timber extraction will vary greatly between regions. All these results suggest that the future of parrots is subject to policymaking in specific countries, and so decision making is especially important in countries sharing the eastern Amazon Basin, New Guinea, Indonesia, and Australia, as it was shown for many other key groups of species (Soares-Filho et al., 2006; Miranda, Imperatriz-Fonseca, \& Giannini, 2019).

This article is protected by copyright. All rights reserved 
We highlighted the northeastern Andes and southeastern Australia as two of the most important hotspots for parrot conservation, however the current situation of these areas is not reassuring. They had high deforestation rates during the last decades (Hansen et al., 2013) and have a worrying future (Clerici et al., 2019; Sharpes et al., 2016) under problematic conservation policies (Clerici et al., 2019). According to our predictions, the change in land-use could strongly compromise most of the distributions of threatened parrot species sensitive to these changes. This could have a drastic effect on parrots by 2050 if we consider that many species will overlap with the increased land-use, which in turn will increase their conservation status by crossing thresholds imposed by the B1 criterion of IUCN. It is very important to take into consideration that we did not consider the effect of climate change on species distributions, which could have an accelerating effect on future land-use changes (Miranda et al. 2019; Northrup et al. 2019), generating even larger changes in the conservation status of parrots to that estimated here. Considering the already Endangered and Critically Endangered parrot species, this poses an extremely elevated extinction risk to them in the near future. The extinction of parrot species may entail the deterioration or loss of some ecological functions, such as long-distance dispersal of large trees (e.g. Tella et al. 2015; Blanco et al. 2016; Tella, Blanco, Dénes, \& Hiraldo, 2019). The conservation of ecosystem function and the great diversity in these two regions may be planned using parrots as surrogate (or umbrella) species given several characteristics that the group represent (i.e. high richness and endemism, their conservation problems, the empathy that they generate in humans, and their usefulness as charismatic fauna).

Importantly, in the phylogenetic context of parrots, Australasia and Oceania (especially New Guinea and southeast Australia) are especially relevant for their conservation (Provost et al., 2017), hosting three endemic parrot families. The rough terrain of New Guinea indirectly protects many parrot species from land-use change, as they are mainly confined to its mountainous regions, but the western side of the island belonging to Indonesia is experiencing very high timber extraction that may represent an unevaluated threat (Fig. 1B). This further supports the assumptions of Olah et al. (2018) that the surprisingly low number of threatened parrot species in New Guinea is mainly given by the lack of information about those species and the threats they are facing, and that further evaluation might lead to revisions of their conservation status. The situation of the Australian parrot conservation hotspot is much more uncertain. Currently, this hotspot is mostly overlapped with human-modified

This article is protected by copyright. All rights reserved 
landscapes (Fig. 1B) and land-use increase is expected in this area (Verburg et al., 2011). Given the current situation of shortage of forest remnants, the future of the group will depend on the rate of forest loss and other stochastic factors as well as natural disturbances (e.g. frequency of fires which are especially high in the region) or biological invasions (Heinsohn et al., 2015).

Considering the predictions for agricultural expansions for the near future, it is expected that land-use changes will have a great general impact on the conservation status of parrots worldwide. Most of the forest dependent parrot species that are expected to increase their conservation status considering the criterion B1 of IUCN by 2050 (Fig. 4) are mainly distributed in the Neotropics and southeastern Australia, and secondarily in the West Indies, the northeastern Andes, and the Atlantic Forest regions. There are also many island endemic species expected to experience great habitat reductions. From the 16 species that are expected to cross a threshold of IUCN in these regions, six are categorized as Least Concerned and four as Near Threatened, with most of them distributed in archipelagos of the Moluccas, Timor, and the Solomon Islands. In addition, six species with higher categories of threat are also distributed in the Solomon Islands, Moluccas, the Philippines, and Fiji. Many of these species will not only experience habitat reduction but also be threatened by invasive alien species that increase their extinction risk (Olah et al., 2018). Finally, regarding African parrots, there are only a few species inhabiting small areas (close to $20,000 \mathrm{~km}^{2}$ in total), but a large proportion of them (3-6 species) will experience some habitat destruction, most of which will predictably happen in central Africa.

Timber extraction is another important threat to parrots, which can adversely affect their natural populations in the long term, given their strong dependence on nest hollows for reproduction. Traditionally, this threat was mainly evaluated locally on a case by case basis (e.g. Heinsohn, Murphy, \& Legge, 2003; Olah, Vigo, Heinsohn, \& Brightsmith, 2014) but here we analyzed it on a global scale. The current trend is worrying, as a very high rate of timber extraction occurs over a large area of the Amazon Basin, the most important hotspot for parrot conservation. Additionally, timber extraction is directly associated with poaching, one of the main threats to neotropical parrot species (Berkunsky et al., 2017). Moreover, our predictions showed that timber extraction will affect an even larger area of the Amazon Basin by 2050, elevating this already important parrot conservation hotspot to an even higher priority. Other important hotspots for parrot conservation are also predicted to suffer 
a similar fate due to timber extraction, including New Guinea, central Africa, and southeastern Australia. In summary, our results warn that timber extraction can be seen as one of the most important threats for parrots and is occurring in key areas for their conservation. Considering that many timber extraction activities are illegal, and when legal are frequently associated with other illegal activities like poaching, there must be strict governmental regulations of timber extraction activities with efficient law enforcement, especially in the mentioned key areas.

The global system of PAs should also play an essential role in maintaining populations of threatened and key species free from human-modified encroachments. Unfortunately, this is not the case for parrots. We highlighted that, in fact, the most threatened group of parrots (CR) is the least represented in PAs globally and also locally in each region (Fig. 3). It is important to consider that we worked with range map polygons, and despite the fact that they were corrected using elevation ranges, our results could include some errors (see Peterson et al. 2017). Hence, the overlap with PAs could be even smaller than reported here. This is an additional proof of the inefficiency of PAs at the global scale, i.e. not efficiently protecting nearly $85 \%$ of the threatened terrestrial vertebrates (Rodrigues et al., 2004; Venter et al., 2014; Jones et al. 2018), specifically the diversity of birds (Vergara-Tabares et al., 2018; De Klerk, Fjeldså, Blyth, \& Burgess, 2004). Historically, the conservation of biodiversity has not been the primal criteria for establishing PAs (Pressey et al., 2002; Rodrigues et al., 2004; Nori et al., 2018), and today most of them are still located in residual places where the potential for extractive uses is low (Devillers et al., 2015). The predominantly residual nature of PAs (mainly in developing and highly diverse countries) is one reason why species continue to go extinct, even when most countries have increased the number and extent of established PAs over the past 10 years (Watson et al., 2014). Here, we are providing important information about key and vulnerable places which could be used to efficiently expand the current network of PAs.

Analyzing parrot distributions, their diversity, habitat dependence, and conservation status, here we have presented a global overview of conservation hotspots and conservation trends of this highly diverse, charismatic, and most threatened group of birds. Unfortunately, the degree of deterioration of many parrot conservation hotspots is (and will continue to be) high. In addition, it is expected that the current global changes may generate further increases in the conservation status of most parrot species, pushing many of them to the brink of extinction. PAs seem not to play a 
significant role in reverting, stopping, or even slowing down this process at the moment. Our negative predictions may induce new challenges in the right moment, when the concern for nature conservation is high and PAs are increasing worldwide (Watson, Grantham, Wilson, \& Possingham, 2011; Jones et al. 2018). The future of wild living parrots is strongly subject to the future management of highlighted parrot conservation hotspots, especially in southern Australia and the Amazon Basin. In these hotspots, decision-makers should use the flagship image of parrots as a tool for guiding conservation policies.

\section{Acknowledgements}

J. N. thanks FONCyT (PICT-2017-2666) and SECyT-UNC for financial support. D. L. V-T. is a postdoctoral fellow at CONICET. M. C. is a CONICET doctoral fellowship holder. J. N. is researcher at CONICET. We thank Suzi Bond and two anonymous reviewers for reading drafts of the manuscript and Linda Alpern for her participation in the design of the graphical abstract.

\section{Data Sharing and Data Accessibility}

R code and data from this study are available upon request to D.L.V-T. (davidlautarov@gmail.com)

\section{References}

Bennett, P. M., \& Owens, I. P. F. (1997). Variation in extinction risk among birds: Chance or evolutionary predisposition? Proceedings of the Royal Society of London. Series B: Biological Sciences, 264(1380), 401-408. doi:10.1098/rspb.1997.0057

Berkunsky, I., Quillfeldt, P., Brightsmith, D. J., Abbud, M. C., Aguilar, J. M. R. E., Alemán-Zelaya, U., ... Masello, J.F. (2017). Current threats faced by Neotropical parrot populations. Biological Conservation, 214, 278-287. doi:10.1016/j.biocon.2017.08.016

BirdLife International and Handbook of the Birds of the World (2018) Bird species distribution maps of the world. Version 2018.1. Available at http://datazone.birdlife.org/species/requestdis.

This article is protected by copyright. All rights reserved 
Bivand, R., Lewin-Koh, N., Pebesma, E. J., Archer, E., Baddeley, A., Bibiko, H. J., ... Turner, R. (2017) Package: 'Maptools'. $\mathrm{R}$ package version 0.9-4. http://CRAN.Rproject.org/package $=$ maptools

Blanco, G., Bravo, C., Pacifico, E. C., Chamorro, D., Speziale, K. L., Lambertucci, S. A., ... \& Tella, J. L. (2016). Internal seed dispersal by parrots: an overview of a neglected mutualism. PeerJ, 4, e1688.

Brodie, J. F., Giordano, A. J., Zipkin, E. F., Bernard, H., Mohd-Azlan, J., \& Ambu, L. (2014). Correlation and persistence of hunting and logging impacts on tropical rainforest mammals. Conservation Biology, 29(1), 110-121. doi:10.1111/cobi.12389

Brooks, T. M., Mittermeier, R. A., Mittermeier, C. G., Da Fonseca, G. A. B., Rylands, A. B., Konstant, W. R., ... Hilton-Taylor, C. (2002). Habitat loss and extinction in the hotspots of biodiversity. Conservation Biology, 16, 909-923. doi: 10.1046/j.1523-1739.2002.00530.x

Brook, B. W., Sodhi, N. S., \& Bradshaw, C. J. (2008). Synergies among extinction drivers under global change. Trends in ecology \& evolution, 23(8), 453-460.

Butchart, S. H., Stattersfield, A. J., Bennun, L. A., Shutes, S. M., Akçakaya, H. R., Baillie, J. E., ... \& Mace, G. M. (2004). Measuring global trends in the status of biodiversity: Red List Indices for birds. PLoS Biology, 2(12).

Ceballos, G., Ehrlich, P. R., Barnosky, A. D., García, A., Pringle, R. M., \& Palmer, T. M. (2015). Accelerated modern human-induced species losses: Entering the sixth mass extinction. Science Advances, 1(5), e1400253.

Chini, L.P., Hurtt, G.C., and Frolking, S. (2014). Harmonized Global Land Use for Years 1500 2100, V1. Data set. Available on-line [http://daac.ornl.gov] from Oak Ridge National Laboratory Distributed Active Archive Center, Oak Ridge, Tennessee, USA. doi: 10.3334/ORNLDAAC/1248

Clerici, N., Salazar, C., Pardo-Díaz, C., Jiggins, C. D., Richardson, J. E., \& Linares, M. (2019). Peace in Colombia is a critical moment for Neotropical connectivity and conservation: Save the northern Andes-Amazon biodiversity bridge. Conservation Letters, 12(1), e12594.

This article is protected by copyright. All rights reserved 
Cockle, K. L., Martin, K., \& Drever, M. C. (2010). Supply of tree-holes limits nest density of cavitynesting birds in primary and logged subtropical Atlantic forest. Biological Conservation, 143(11), 2851-2857. doi: 10.1016/j.biocon.2010.08.002

Collar, N. (2018). Psittaciformes. In: del Hoyo, J., Elliott, A., Sargatal, J., Christie, D.A. \& de Juana, E. (eds.). Handbook of the Birds of the World Alive. Lynx Edicions, Barcelona. (retrieved from https://www.hbw.com/node/52256 on 31 May 2018).

Cullen Jr, L., Bodmer, R. E., \& Pádua, C. V. (2000). Effects of hunting in habitat fragments of the Atlantic forests, Brazil. Biological Conservation, 95(1), 49-56. doi: 10.1016/S00063207(00)00011-2

De Klerk, H. M., Fjeldså, J., Blyth, S., \& Burgess, N. D. (2004). Gaps in the protected area network for threatened Afrotropical birds. Biological Conservation, 117(5), 529-537.

del Hoyo, J., Collar, N. J., Christie, D. A., Elliott, A. and Fishpool, L. D. C. (2014). HBW and BirdLife International Illustrated Checklist of the Birds of the World. Volume 1: Nonpasserines. Lynx Edicions and BirdLife International, Barcelona, Spain and Cambridge, UK.

Devillers, R., Pressey, R. L., Grech, A., Kittinger, J. N., Edgar, G. J., Ward, T., \& Watson, R. (2015). Reinventing residual reserves in the sea: are we favouring ease of establishment over need for protection? Aquatic Conservation: Marine and Freshwater Ecosystems, 25(4), 480-504.

Ellis, E. C., Goldewijk, K., Siebert, S., Lightman, D., \& Ramankutty, N. (2010). Anthropogenic transformation of the biomes, 1700 to 2000. Global ecology and biogeography, 19(5), 589-606.

ESA Climate Change Initiative (2017). https://www.esa-landcover-cci.org/, ESA, 2018, accessed on May 9th, 2018.

Ficetola, G. F., Rondinini, C., Bonardi, A., Katariya, V., Padoa-Schioppa, E., \& Angulo, A. (2014). An evaluation of the robustness of global amphibian range maps. Journal of Biogeography, 41(2), 211-221.

Ficetola, G. F., Mazel, F., \& Thuiller, W. (2017). Global determinants of zoogeographical boundaries. Nature Ecology \& Evolution, 1(4), 0089.

Fischer, J., \& Lindenmayer, D. B. (2007). Landscape modification and habitat fragmentation: a synthesis. Global Ecology Biogeography, 17, 265-280. doi: 10.1111/j.1466-8238.2007.00287.x

This article is protected by copyright. All rights reserved 
Fleishman, E., Murphy, D. D., \& Brussard, P. F. (2000). A new method for selection of umbrella species for conservation planning. Ecological applications, 10(2), 569-579.

Foley, J. A. (2005). Global consequences of land use. Science, 309, 570-574. doi: $10.1126 /$ science. 1111772

Forshaw, J. M. (2010). Parrots of the World (Vol. 70). Princeton University Press.

Forshaw, J., \& Knight, F. (2017). Vanished and Vanishing Parrots: Profiling Extinct and Endangered Species. CSIRO PUBLISHING.

Gibson, L., Lee, T. M., Koh, L. P., Brook, B. W., Gardner, T. A., Barlow, J., ... Sodhi, N. S. (2011). Primary forests are irreplaceable for sustaining tropical biodiversity. Nature, 478, 378-381. doi: 10.1038/nature10425

Hansen, M. C., Potapov, P. V., Moore, R., Hancher, M., Turubanova, S. A., Tyukavina, A., ... Townshend, J. R. G. (2013). High-resolution global maps of 21st-century forest cover change. Science, 342, 850-853. doi: 10.1126/science.1244693

Hansen, M. C., P. V. Potapov, R. Moore, M. Hancher, S. A. Turubanova, A. Tyukavina, D. Thau, S. V. Stehman, S. J. Goetz, T. R. Loveland, A. Kommareddy, A. Egorov, L. Chini, C. O. Justice, and J. R. G. Townshend. (2013). "High-Resolution Global Maps of 21st-Century Forest Cover Change.” Science 342 (15 November): 850-53. Data available on-line from: http://earthenginepartners.appspot.com/science-2013-global-forest.

Hanski, I., Zurita, G. A., Bellocq, M. I., \& Rybicki, J. (2013). Species-fragmented area relationship. Proceedings of the National Academy of Sciences, 110(31), 12715-12720.

Hayhoe, K., J. Edmonds, R.E. Kopp, A.N. LeGrande, B.M. Sanderson, M.F. Wehner, and D.J. Wuebbles, (2017). Climate models, scenarios, and projections. In: Climate Science Special Report: Fourth National Climate Assessment, Volume I [Wuebbles, D.J., D.W. Fahey, K.A. Hibbard, D.J. Dokken, B.C. Stewart, and T.K. Maycock (eds.)]. U.S. Global Change Research Program, Washington, DC, USA, pp. 133-160, doi: 10.7930/J0WH2N54.

Heinsohn, R., Buchanan, K. L., \& Joseph, L. (2018). Parrots move to centre stage in conservation and evolution. Emu - Austral Ornithology, 118, 1-6.

This article is protected by copyright. All rights reserved 
Heinsohn, R., Murphy, S., \& Legge, S. (2003). Overlap and competition for nest holes among eclectus parrots, palm cockatoos and sulphur-crested cockatoos. Australian Journal of Zoology, 51(1), 81-94.

Heinsohn, R., Webb, M., Lacy, R., Terauds, A., Alderman, R., \& Stojanovic, D. (2015). A severe predator-induced population decline predicted for endangered, migratory swift parrots (Lathamus discolor). Biological Conservation, 186, 75-82.

Hijmans, R. J., van Etten, J., Cheng, J., Mattiuzzi, M., Sumner, M., Greenberg, J. A., ... \& Hijmans, M. R. J. (2015). Package 'raster'. R package.

Hosonuma, N., Herold, M., De Sy, V., De Fries, R. S., Brockhaus, M., Verchot, L., ... \& Romijn, E. (2012). An assessment of deforestation and forest degradation drivers in developing countries. Environmental Research Letters, 7(4), 044009.

Hurtt, G.C., L.P. Chini, S. Frolking, R. A. Betts, J. Feddema, G. Fischer, J. P. Fisk, K. Hibbard, R. A. Houghton, A. Janetos, C. D. Jones, G. Kindermann, T. Kinoshita, K. Klein Goldewijk, K. Riahi, E. Shevliakova, S. Smith, E. Stehfest, A. Thomson, P. Thornton, D. P. van Vuuren, Y. P. Wang. 2011. Harmonization of land-use scenarios for the period 1500-2100: 600 years of global gridded annual land-use transitions, wood harvest, and resulting secondary lands. Climatic Change, 109:117-161. doi: 10.1007/s10584-011-0153-2

IUCN (2012). IUCN Red List Categories and Criteria: Version 3.1. Second edition. Gland, Switzerland and Cambridge, UK: IUCN.

IUCN (2018). The IUCN red list of threatened species. Version 2018-1. Retrieved from http://www.iucnredlist.org

IUCN \& UNEP (2019). The World Database of Protected Areas (WDPA). Cambridge, UK: UNEPWCMC. Retrieved from www.protectedplanet.net

Jetz, W., Wilcove, D. S., \& Dobson, A. P. (2007). Projected impacts of climate and land-use change on the global diversity of birds. PLoS Biology, 5(6). doi: 10.1371/journal.pbio.0050157

Jones, K. R., Venter, O., Fuller, R. A., Allan, J. R., Maxwell, S. L., Negret, P. J., Watson, J. E. (2018). One-third of global protected land is under intense human pressure. Science, 360, 788-791.

This article is protected by copyright. All rights reserved 
Martin, R. O. (2018). Grey areas: temporal and geographical dynamics of international trade of Grey and Timneh Parrots (Psittacus erithacus and P. timneh) under CITES. Emu - Austral Ornithology, 118(1), 113-125. doi: 10.1080/01584197.2017.1369854

Martin, R. O., Perrin, M. R., Boyes, R. S., Abebe, Y. D., Annorbah, N. D., Asamoah, A., ... \& Diop, M. S. (2014). Research and conservation of the larger parrots of Africa and Madagascar: a review of knowledge gaps and opportunities. Ostrich, 85(3), 205-233.

Miranda, L. S., Imperatriz-Fonseca, V. L., \& Giannini, T. C. (2019). Climate change impact on ecosystem functions provided by birds in southeastern Amazonia. PLoS ONE, 14(4): e0215229. doi: 10.1371 journal.pone.0215229

Newton, I. (1994). The role of nest sites in limiting the numbers of hole-nesting birds: a review. Biological Conservation, 70, 265-276. doi:10.1016/0006-3207(94)90172-4

Nori, J., Villalobos, F. \& Loyola, R. (2018). Global priority areas for amphibian research. Journal of Biogeography, 45, 2588-2587.

Nori, J., \& Loyola, R. (2015). On the Worrying Fate of Data Deficient Amphibians. PLoS ONE, 10(5), e0125055. doi: 10.1371/journal.pone.0125055

Nori, J., Lemes, P., Urbina-Cardona, N., Baldo, D., Lescano, J., \& Loyola, R. (2015). Amphibian conservation, land-use changes and protected areas: A global overview. Biological Conservation, 191, 367-374. doi: 10.1016/j.biocon.2015.07.028

Northrup, J. M., Rivers, J. W., Yang, Z., \& Betts, M. G. (2019). Synergistic effects of climate and land-use change influence broad-scale avian population declines. Global Change Biology, 25(5), 1561-1575.

Laurance, W. F., Carolina Useche, D., Rendeiro, J., Kalka, M., Bradshaw, C. J. A., Sloan, S. P., ... Zamzani, F. (2012). Averting biodiversity collapse in tropical forestprotected areas. Nature, 489, 290-294. doi: 10.1038/nature11318

O’Neill, B. C., Kriegler, E., Ebi, K. L., Kemp-Benedict, E., Riahi, K., Rothman, D. S., ... \& Levy, M. (2017). The roads ahead: Narratives for shared socioeconomic pathways describing world futures in the 21 st century. Global Environmental Change, 42, 169-180. doi: 10.1016/j.gloenvcha.2015.01.004

This article is protected by copyright. All rights reserved 
Olah, G., Butchart, S. H. M., Symes, A., Guzmán, I. M., Cunningham, R., Brightsmith, D. J., \& Heinsohn, R. (2016). Ecological and socio-economic factors affecting extinction risk in parrots. Biodiversity and Conservation, 25, 205-223. doi:10.1007/s10531-015-1036-Z

Olah, G., Theuerkauf, J., Legault, A., Gula, R., Stein, J., Butchart, S., ... \& Heinsohn, R. (2018). Parrots of Oceania-a comparative study of extinction risk. Emu-Austral Ornithology, 118(1), 94-112.

Olah, G., Vigo, G., Heinsohn, R., \& Brightsmith, D. J. (2014). Nest site selection and efficacy of artificial nests for breeding success of Scarlet Macaws Ara macao macao in lowland Peru. Journal for Nature Conservation, 22(2), 176-185.

Peterson, A. T. (2017). Problems with reductive, polygon-based methods for estimating species' ranges: reply to Pimm et al. 2017. In Conservation Biology (Vol. 31, Issue 4, pp. 948-951). John Wiley \& Sons, Ltd (10.1111). https://doi.org/10.1111/cobi.12929

Pires, S. F. (2012). The illegal parrot trade: a literature review. Global Crime, 13, 176-190.

Pollock, L. J., Thuiller, W., \& Jetz, W. (2017). Large conservation gains possible for global biodiversity facets. Nature, 546(7656), 141-144.

Pressey, R.L., Visconti, P. \& Ferraro, P.J. (2015). Making parks make a difference: poor alignment of policy, planning and management with protected-area impact, and ways forward. Philosophical Transactions of the Royal Society of London. Series B, Biological Sciences, 370, 1-19

Pressey, R. L., Whish, G. L., Barrett, T. W., \& Watts, M. E. (2002). Effectiveness of protected areas in northern New South Wales: recent trends in six measures. Biological Conservation, 106, 5769. doi: 10.1016/S0006-3207(01)00229-4

Prieto-Torres, D. A., Nori, J., \& Rojas-Soto, O. R. (2018). Identifying priority conservation areas for birds associated to endangered Neotropical dry forests. Biological Conservation, 228, 205-214.

Provost, K. L., Joseph, L., \& Smith, B. T. (2017). Resolving a phylogenetic hypothesis for parrots: implications from systematics to conservation. Emu - Austral Ornithology, 118(1), 7-21. doi:10.1080/01584197.2017.1387030

R Core Team (2014) R: a language and environment for statistical computing. R Foundation for Statistical Computing, Vienna

This article is protected by copyright. All rights reserved 
Ripple, W. J., Abernethy, K., Betts, M. G., Chapron, G., Dirzo, R., Galetti, M., ... \& Newsome, T. M. (2016). Bushmeat hunting and extinction risk to the world's mammals. Royal Society Open Science, 3(10), 160498.

Rodrigues, A. S. L., Andelman, S. J., Bakarr, M. I., Boitani, L., Brooks, T. M., Cowling, R. M., ... Da Fonseca, G. A. B. (2004). Effectiveness of the global protected area network in representing species diversity. Nature, 428, 640-643. doi: 10.1038/nature02422

Sala, O. E., Chapin, F. S. III, Armesto, J. J., Berlow, E., Bloomfield, J., Dirzo, R., ... Wall, D. H. (2000). Global biodiversity scenarios for the year 2100. Science, 287, 1770-1774. doi: $10.1126 /$ science.287.5459.1770

Sharples, J. J., Cary, G. J., Fox-Hughes, P., Mooney, S., Evans, J. P., Fletcher, M. S., ... \& Baker, P. (2016). Natural hazards in Australia: extreme bushfire. Climatic Change, 139(1), 85-99.

Tella, J. L., Baños-Villalba, A., Hernández-Brito, D., Rojas, A., Pacífico, E., Díaz-Luque, J. A., ... \& Hiraldo, F. (2015). Parrots as overlooked seed dispersers. Frontiers in Ecology and the Environment, 13(6), 338-339.

Tella, J. L., Blanco, G., Dénes, F. V., \& Hiraldo, F. (2019). Overlooked parrot seed dispersal in Australia and South America: insights on the evolution of dispersal syndromes and seed size in Araucaria trees. Frontiers in Ecology and Evolution, 7, 82.

Torres, P. C., Morsello, C., Parry, L., Barlow, J., Ferreira, J., Gardner, T., \& Pardini, R. (2018). Landscape correlates of bushmeat consumption and hunting in a post-frontier Amazonian region. Environmental Conservation, 45(4), 315-323. doi: 10.1017/S0376892917000510

Scholes, R. J., Montanarella, L., Brainich, E., Brainich, E., Barger, N., ten Brink, B., ... Willemen, L. (Eds.) (2018). IPBES (2018): Summary for policymakers of the assessment report on land degradation and restoration of the Intergovernmental Science- Policy Platform on Biodiversity and Ecosystem Services. Bonn, Germany: Intergovernmental Science-Policy Platform on Biodiversity and Ecosystem Services.

Sloan, S., \& Sayer, J. A. (2015). Forest Resources Assessment of 2015 shows positive global trends but forest loss and degradation persist in poor tropical countries. Forest Ecology and Management, 352, 134-145.

This article is protected by copyright. All rights reserved 
Snyder, N., McGowan, P., Gilardi, J., \& Grajal, A. (2000). Parrots. Status Survey and Conservation Action Plan 2000-2004. IUCN, Gland, Switzerland and Cambridge, UK.

Soares-Filho, B. S., Nepstad, D. C., Curran, L. M., Cerqueira, G. C., Garcia, R. A., Ramos, C. A., ... \& Schlesinger, P. (2006). Modelling conservation in the Amazon basin. Nature, 440(7083), 520.

Van Asselen, S., \& Verburg, P. H. (2013). Land cover change or land-use intensification: simulating land system change with a global-scale land change model. Global Change Biology, 19(12), 3648-3667.

Van Vliet, J., \& Verburg, P. H. (2018). A short presentation of CLUMondo. In Geomatic Approaches for Modeling Land Change Scenarios (pp. 485-492). Springer, Cham.

Venter, O., Fuller, R. A., Segan, D. B., Carwardine, J., Brooks, T., Butchart, S. H., ... \& Possingham, H. P. (2014). Targeting global protected area expansion for imperiled biodiversity. PLoS Biology, 12(6), e1001891.

Verburg, P. H., Ellis, E. C., \& Letourneau, A. (2011). A global assessment of market accessibility and market influence for global environmental change studies. Environmental Research Letters, 6, 034019.

Vergara-Tabares, D. L., Lammertink, M., Verga, E. G., Schaaf, A. A., \& Nori, J. (2018). Gone with the forest: Assessing global woodpecker conservation from land use patterns. Diversity and Distributions, 24(5), 640-651.

Vieira, R. R., Pressey, R. L., \& Loyola, R. (2019). The residual nature of protected areas in Brazil. Biological conservation, 233, 152-161.

Watson, J.E., Grantham, H.S., Wilson, K.A., Possingham, H.P., 2011. Systematic conservation planning: past, present and future. In: Whittaker, R., Ladle, R. (Eds.), Conservation Biogeography. Wiley-Blackwell. New Jersy, USA, pp. 136-160.

Watson, J. E., Dudley, N., Segan, D. B., \& Hockings, M. (2014). The performance and potential of protected areas. Nature, 515(7525), 67.

White, T. H. Jr., Collazo, J. A., \& Vilella, F. J. (2005). Survival of captive-reared Puerto Rican parrots released in the Caribbean National Forest. The Condor, 107, 424-432.

Wiebe, K. L. (2011). Nest sites as limiting resources for cavity-nesting birds in mature forest ecosystems: a review of the evidence. Journal of Field Ornithology, 82(3), 239-248.

This article is protected by copyright. All rights reserved 
Wiley, J. W., Gnam, R. S., Koenig, S. E., Dornelly, A., Gálvez, X., Bradley, P. E., ... \& Anthony, D. (2004). Status and conservation of the family Psittacidae in the West Indies. Journal of Caribbean Ornithology, 17(1), 94-154.

\section{Figure Captions}

Figure 1. Maps of conservation hotspots for parrot conservation in relation to land use. Color gradients indicate the overlap of maximum existing/expected weighted richness for parrot species with different land use: green gradient represents non-modified areas; purple gradient represents human-modified areas (intensive agriculture and urban areas). Darker areas indicate greater weighted richness for both color gradients. Global maps cover (A) Central- and South America; (B) Australasia and Oceania; and (C) Africa, in three different temporal scenarios analyzed. Box plots indicate the loss of area per conservation status including all parrot species distributed on the associated map. Lines in boxes are medians, boxes indicate $25^{\text {th }}$ and $75^{\text {th }}$ percentiles, whiskers indicate the data range, and points are outliers.

Figure 2. Maps of conservation hotspots for parrot conservation in relation to timber extraction. Color gradients indicate the overlap of maximum existing/expected weighted richness for parrot species with different levels of timber extraction: green gradient represents areas with low or null timber extraction (proxy of logging and poaching); purple gradient represents areas with high timber extraction (defined by the limits of the third quartile of timber extraction distribution); and red gradient represents areas with very high timber extraction (defined by the fourth quartile of timber extraction). Darker areas indicate greater weighted richness for all color gradients. Global maps cover (A) Central- and South America; (B) Australasia and Oceania; and (C) Africa. Box plots indicate the timber extraction $\left(\mathrm{Ton} / \mathrm{km}^{2}\right)$ per conservation status including all parrot species distributed on the associated map. Lines in boxes are medians, boxes indicate $25^{\text {th }}$ and $75^{\text {th }}$ percentiles, whiskers indicate the data range, and points are outliers.

This article is protected by copyright. All rights reserved 
Figure 3. Average overlap of the geographic range of parrot species with protected areas, partitioned by global regions and the conservation status of the species. The values were calculated using the land cover map of 2018 .

Figure 4. Current and predicted conservation status of forest dependent parrot species. Internal circles represent each forest dependent parrot species that has less than $20,000 \mathrm{~km}^{2}$ of range distribution occupied by non-human dominated habitat. The surface of each circle indicates the log of the surface in $\mathrm{km}^{2}$. External circles (in bold) represent the thresholds from the criterion B1 for conservation status. The species circles were partitioned by geographic region and period (present and future). Species acronyms for 2050 in purple letters indicate that the species will decrease habitat surface overstepping the threshold for conservation status (B1 criterion). Acronyms in blue indicate an expected increase in habitat surface. Different colors of species circles indicate the current conservation status of IUCN. Acronyms represent the following species for each region analyzed: Central and South America: Amazona agilis (AMAG), A. collaria (AMCO), A. leucocephala (AMLE), A. petrei (AMPR), A. rhodocorytha (AMRH), A. ventralis (AMVE), Brotogeris pyrrhoptera (BRPY), Eupsittula nana (EUNA), Forpus spengeli (FOSP), F. xanthops (FOXA), Hapalopsittaca fuertesi (HAFU), H. pyrrhops (HAPY), Pyrrhura albipectus (PYAL), P. caeruleiceps (PYCA), P. calliptera (PYCAL), P. eisenmanni (PYEI), P. emma (PYEM), P. hoematotis (PYHO), P. hoffmanni (PYHOF), P. orcesi (PYOR), P. pfrimeri (PYPF), P. rhodocephala (PYRH), P. subandina (PYSU), P. viridicata (PYVI), Rynchopsitta terrisi (RYTE), Touit costaricensis (TOCO), T. melanonotus (TOME), and Triclaria malachitacea (TRMA). Australasia and Oceania: Aprosmictus jonquillaceus (APJO), Cacatua alba (CAAL), C. ducorpsii (CADU), C. moluccensis (CAMO), Chalcopsitta cardinalis (CHCA), Charmosyna diadema (CHDI), C. margarethae (CHMA), C. meeki (CHME), C. palmarum (CHPA), C. papou (CHPAP), C. toxopei (CHTO), Eos bornea (EOBO), E. cyanogenia (EOCY), E. histrio (EOHI), E. reticulata (EORE), E. semilarvata (EOSE), E. squamata (EOSQ),

Geoffroyus hyacinthinus (GEHY), Loriculus amabilis (LOAM), L. flosculus (LOFL), L. pusillus (LOPU), Lorius albidinucha (LOAL), L. chlorocercus (LOCH), L. domicella (LODO), L. garrulous (LOGA), Micropsitta geelvinkiana (MIGE), M. meeki (MIME), Prioniturus flavicans (PRFL), P. mada (PRMA), P. mindorensis (PRMI), P. montanus (PRMO), P. platenae (PRPL), P. verticalis

This article is protected by copyright. All rights reserved 
(PRVE), P. waterstradti (PRWA), Prosopeia personata (PRPE), P. splendens (PRSP), Psittacula calthrapae (PSCA), P. caniceps (PSCAN), Psitteuteles iris (PSIR), Psittinus abbotti (PSAB), Tanygnathus gramineus (TAGR), Trichoglossus euteles (TREU), T. flavoviridis (TRFL), and $T$. johnstoniae (TRJO). Africa: Agapornis lilianae (AGLI), A. nigrigenis (AGNI), Coracopsis sibilans (COSI), Poicephalus flavifrons (POFL), Psittacus timneh (PSTI).

This article is protected by copyright. All rights reserved 
(a)

(b)
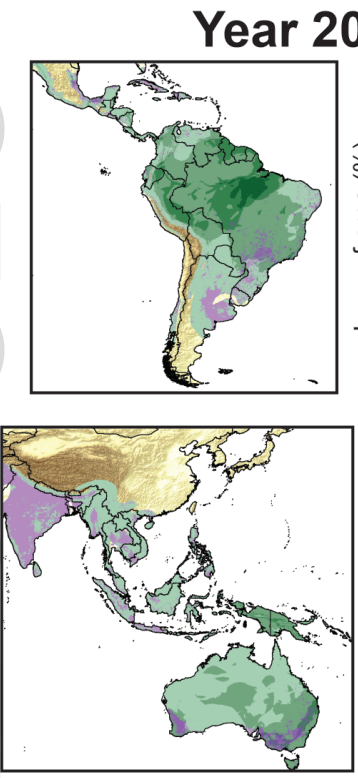

(c)

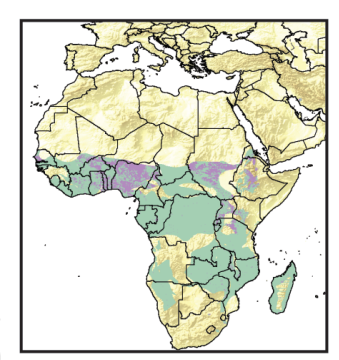

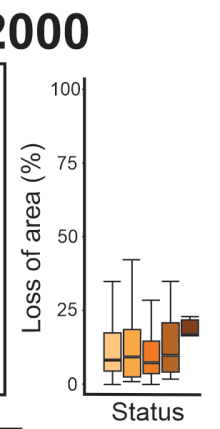
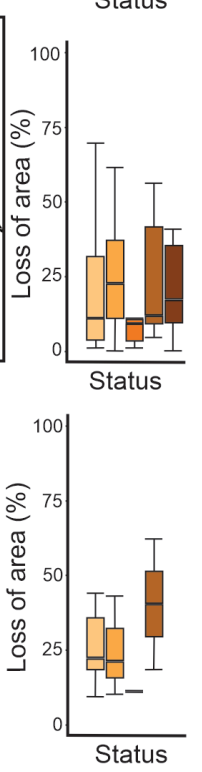

Year 2018
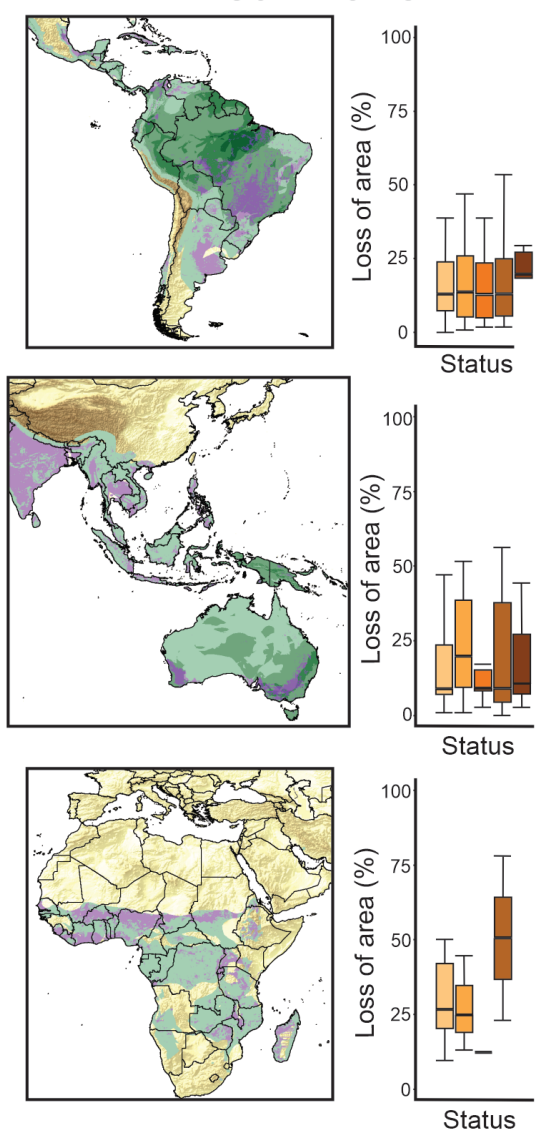

Year 2050
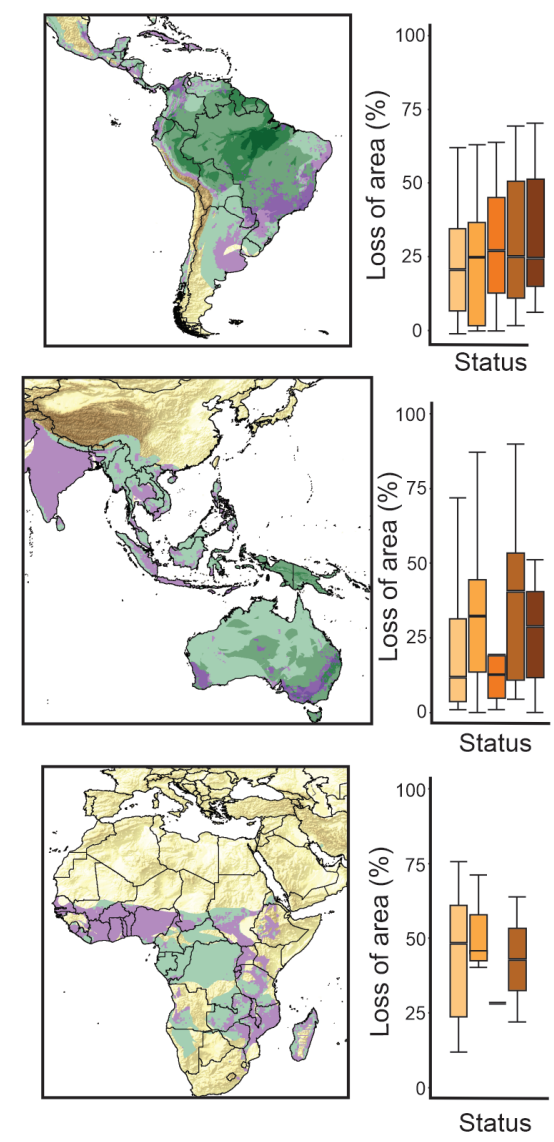

Human-modified Non modified

Weighted Richness

Conservation Status

$\begin{array}{llll}0-10 & 11-20 & 21-30 & >31\end{array}$

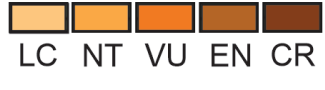

gcb_15135_f1.tif 
(a)

(b)

(c)

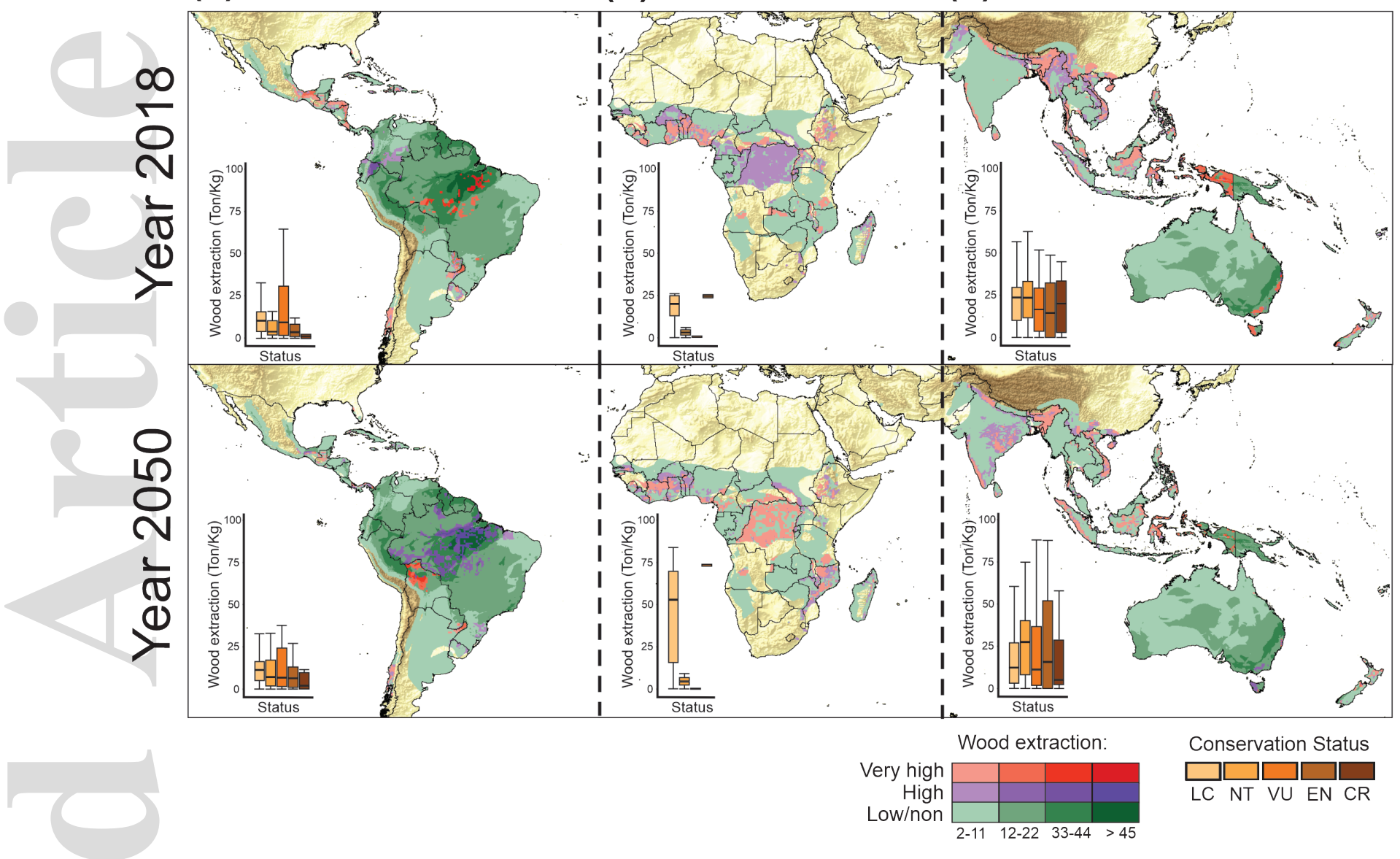

gcb_15135_f2.tif

This article is protected by copyright. All rights reserved 


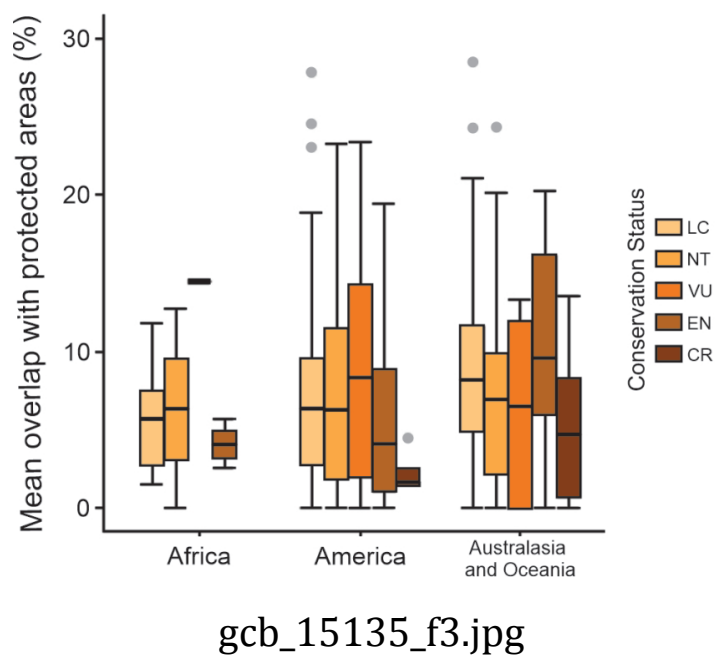

This article is protected by copyright. All rights reserved 

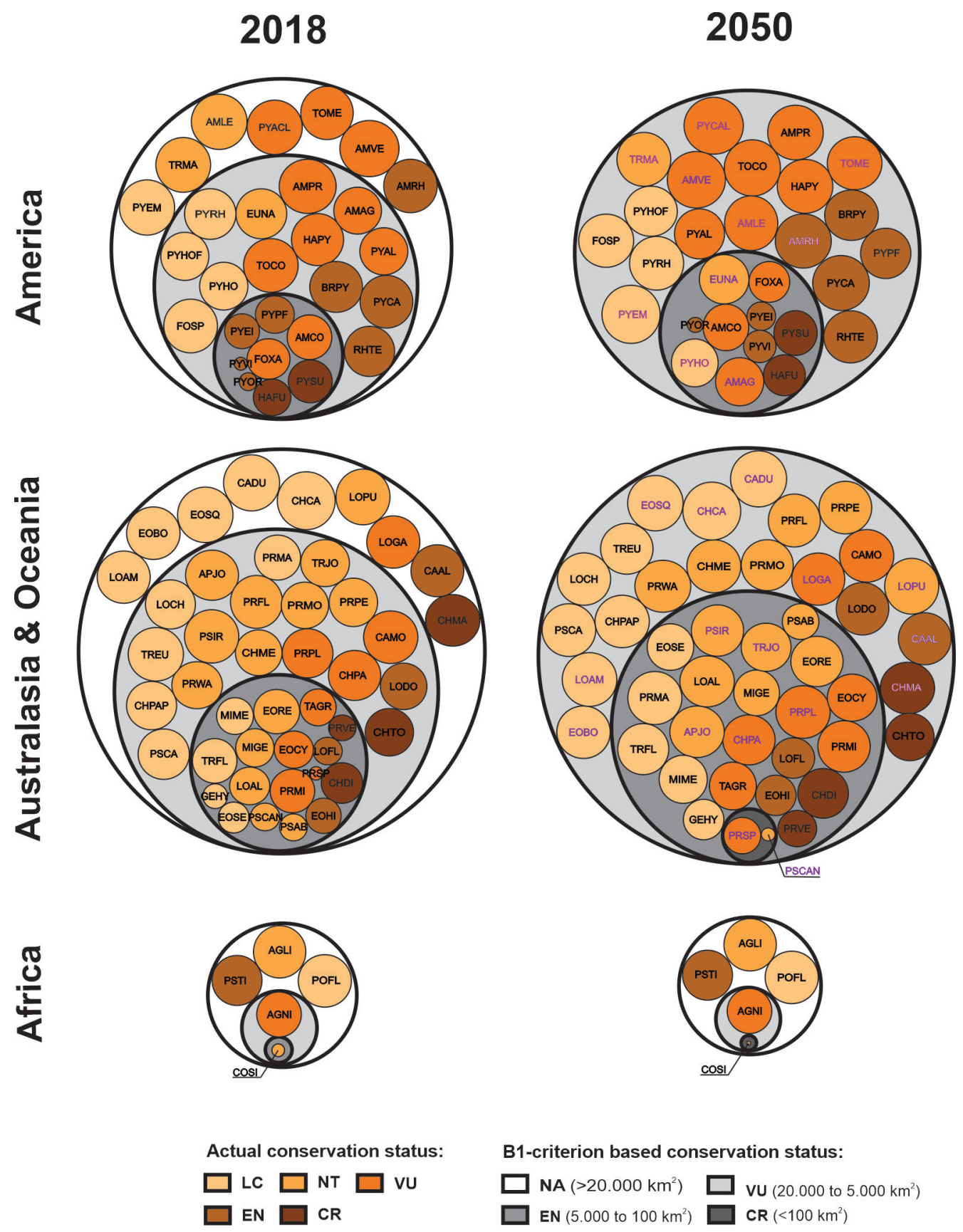

B1-criterion based conservation status:

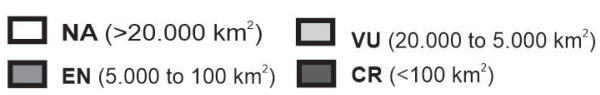

gcb_15135_f4.jpg 